\title{
SMALLHOLDER FARMERS' INNOVATIVENESS AND ITS DETERMINANTS IN EASTERN HARARGHE, OROMIYA REGION, ETHIOPIA
}

\author{
Wesagn BERHANE * (D), Jema HAJI, Belaineh LEGESSE, Tesfaye LEMMA
}

\author{
Address: \\ Haramaya University, Department of Rural Development and Agricultural Extension; \\ Corresponding Author's email: wesagnb@yahoo.com \\ * Corresponding Author's email: wesagnb@yahoo.com
}

\begin{abstract}
The survival of smallholder farming in a socioeconomically and environmentally dynamic environment depends on smallholders' ability to innovatively and dynamically respond to these challenges. This study aims to assess smallholders' innovativeness, and identify its determinants with the intension of providing information on smallholders' innovativeness and its determinants to stakeholders that are trying to improve the life of smallholders. The research design constituted of multi-stage random sampling whereby study districts, farmers' associations and, finally, smallholder farmer household units are selected in that order. The collection of data is carried out using interview schedule, key informants interview and focus group discussion. The estimation of smallholders' innovativeness was carried out with graded response model using cross-sectional data collected from 476 smallholder household units. Multiple linear regression model was used to identify determinants of innovativeness. The results revealed that the majority of smallholders in the study area were classified as less innovative and innovativeness was determined by smallholder's perception of productive safety net program undergoing in the study area, dependency syndrome, perceived farm fertility, perceived job demand, perceived person environment fit, fatalism, external work contact, use of mass media, possession of livestock, possession of farm tools, access to irrigation, agro-ecology and distance to allweather road. In order to encourage smallholders' innovativeness, the findings underscore the need for stakeholders in the extension service to help smallholders on improving their perceptions about productive safety net program, motivate them to see the potential benefit they can draw from personal efforts and resources they have, provide them with external exposure through either mass media means or interpersonal contact, work with religious leaders to detach religiousness from fatalism.
\end{abstract}

Keywords: Innovativeness, Smallholder Farmers

JEL: O31, Q100, R21

\section{INTRODUCTION}

In Ethiopia, smallholder agriculture is characterized by age-old technologies and agricultural management system (EPCC, 2016). Around eight million people who live on this occupation receive support from productive safety net, a program that is targeted at bringing resilience to shocks and livelihoods enhancement, and food security and nutrition improvement, for rural households vulnerable to food insecurity (MoA, 2014; NPC, 2016). Despite the impediments and self-insufficiency, agriculture's contribution to the overall economic growth of the country is paramount as it accounts for $34.9 \%$ of the country's GDP in the year 2017/18 (NBE, 2018), employs about $85 \%$ of the labour force and contributes around 90 percent of the total export earnings (CSA, 2016). If the sector is to satisfactorily and sustainably contribute to the ever growing economic demand of the population, it should develop and be able to adapt itself to ever changing and demanding situations. Agricultural development which demands and depends on innovation and innovation system enables agriculture and people to adapt rapidly when challenges occur and to respond readily when opportunities arise (World Bank, 2012). Innovation is widely recognized as a major source of improved productivity, competitiveness, and economic growth throughout advanced and emerging economies (OECD, 2009a). Innovation involves three elements viz. idea generation, idea promotion and realization. It requires combining a creative idea with resources and expertise that make it possible to embody the creative idea in a useful form. (Janssen, 2000; Schilling, 2017). In rural sectors, the efforts of family farmers to adapt their farming system to local conditions by applying indigenous knowledge which they have experimented and accumulated through time can be considered as a source of rural innovation, a perspective that should be considered in order to develop a concept of innovation that strengthens family farming as part of sustainable rural development (Beduschi et al., 2017). Smallholder farmers' innovation like any other firm is mediated by, among other factors, economic capability and a feeling of enthusiasm, interest, or commitment towards farming as the self-determination theory elaborates the necessity for intrinsic motivation in carrying out a task innovatively (Amabile, 1997) (Deci and Ryan, 1985). As a social protection service, productive safety net program (PSNP) provides an enabling environment conducive to 
innovative agricultural engagement since it enhances the capabilities of smallholders through financial transfer, provision of livelihood support, skills training and behaviour change communication to its beneficiaries (OECD, 2009b; Devereux and Sabates-Wheeler, 2004). PSNP makes transfer, cash and/or food to beneficiaries through its public work, permanent direct support, livelihood transfer and risk management components. In the public work component, households with able-bodied labour are expected to participate in public work tasks and get six months payment while in the permanent direct support component households without adult able-bodied labour are provided with 12 months of free transfer. The other two components are integral parts of the first two (MoA, 2014).Hence, investigating smallholders' innovativeness and its determinants is crucial if Ethiopian economy has to benefit from agriculture in a dependable manner. Nevertheless, in Ethiopia studies on smallholders' innovativeness that considers the perspective of ingeniousness, creativity or inventiveness has not been adequately addressed as the search for similar studies came up only with the works of Gebre and Zegeye (2014) on challenges of farmers' innovativeness and Tirfe (2014) on smallholder farmers' innovation and its determinants in northern part of Ethiopia. Besides, smallholders' innovativeness has been seen by researchers, predominantly, from the perspective of adoption of innovation. Therefore, innovativeness as conceptualized by Lumpkin and Dess (1996) as an individual's (smallholder's) behaviour that aims to achieve the initiation and intentional introduction of new and useful ideas, processes, products or procedures to enhance personal and/or business performance, and its determinants while controlling for the effect of PSNP need to be sufficiently addressed. Therefore, this study provides evidence on smallholders' innovativeness and its determinants to stakeholders that are trying to improve the life of smallholders.

\section{DATA AND METHODS}

\section{Study area}

Oromiya regional state consists of 20 administrative zones including east Hararghe zone which comprises 19 districts. The total population of east Hararghe is estimated at 2,723,850 people of whom 211,606 and 2,502,365 are urban and rural dwellers, respectively (CSA, 2007). The zone is found in the eastern part of Ethiopia. Its capital is Harar, located $510 \mathrm{~km}$ to the east of the Ethiopian capital Addis Ababa. Although the zone has a significant area of land and a relatively large population, it is ranked as the last among all zones of Oromiya region in terms of surface and ground water potential. The zone has two main drainage basins, namely the Wabishebele and Awash drainage basins. Due to the topography and hydro-geological condition, east Hararghe is a water resource scarce area (Jema et al., 2010). It is characterized by plateaus, rugged mountains, deep gorges and flat plains. The altitude ranges from 500 to 3,400 meters above sea level. The zone contains three agro-ecological zones, highlands (elevations above 2,300 m a.s.l), midlands (elevations between 1,500 and 2,300 m a.s.l) and lowlands (below 1,500 $\mathrm{m}$ a.s.1). The lowlands occupies the largest area $(62.2 \%)$, followed by midlands $(26.4 \%)$ and highlands (11.4\%) (Tolossa and Tafesse, 2008). Information collected from zone office of agriculture indicates that PSNP is underway in all districts where there are a total of 115,431 beneficiary households of which 388,036 and 56,729 individuals are supported by the public work and direct support components of the program, respectively. Community member who are chronically food insecure, faced continuous food shortages (3 months of food gap or more per year) in the last 3 years or those who have become suddenly food insecure as a result of a severe loss of assets or those who have no adequate family support and other means of social protection and support are targeted by community food security task force to be PSNP beneficiaries.

\section{Sampling techniques and the data}

The overall sampling design followed multi-stage random sampling where study districts, farmers' associations and households have been selected in that order. Since controlling for the effect of agro-ecological zone and participation in productive safety net program (PSNP) was deemed necessary in analysing determinants of innovativeness, the sampling procedure had taken these factors into consideration. To this effect districts were stratified as lowland and midland firstly, whereas households in both strata were stratified again as PSNP participants and non-participants. Hence, the sampling frame at the household level is constituted of beneficiaries of public work component of PSNP and non-beneficiaries. In the first stage two districts, one from lowland and one from midland agro-ecological zones, were randomly selected among the 19 districts found in the zone. In the second stage, 5 farmers' associations, three from lowland and two from midland areas, considering their proportion of geographical coverage, were randomly chosen. Finally, sample households were randomly selected from a list obtained from the district offices of agriculture and farmer associations' development center offices. Cross-sectional data from 476 randomly selected sample households were collected. The survey was conducted during the period of July - September 2018 in Fedis and Haramaya district. Data were collected with the help of interview schedule, key informant interviews (seven informants, one from each farmers' association and one from each districts) and focus group discussions that is consisted of 5-6 members (two groups from each farmers' association) where participants are identified by development agents (DAs). Focus group discussion was conducted with PSNP participants and non-participants separately. Participants of key informant interviews and focus group discussions were selected based on their informative capacity with regard to the study area and implementation of PSNP. The contents of the information delivered by the participants was analysed and summarized.

\section{Methods of data analysis}

Smallholders' innovativeness was operationally defined to measure the extent to which smallholders' generate and/or utilize novel ideas, champion it, implement it in practice and evaluate its performance. Its measurement was done 
by 8 -items 5 -point scale ranging from 'never' (1) to 'always' (5) based on Janssen (2000). The instrument was modified to suit survey contextual specificity. Innovativeness was assumed to represent a latent trait construct. The use of multiple-category types of itemresponse data were justified for estimation of this construct as these data set are more informative and reliable than dichotomously scored items. Hence, polytomous item response theory (IRT) model was used to represent the nonlinear relation between innovativeness level and the probability of responding in a particular category. The estimations of model parameters for these latent variables were carried out by employing graded response model (GRM).The graded-response model (GRM) is appropriate to use when item responses can be characterized as ordered categorical responses (Embretson and Reise, 2000). The GRM allows the ordered categories to vary between items; assuming the outcome levels for all items are given by $k=0,1, \ldots, K$, the model is specified as follows. In the GRM, each item is modeled with its own discrimination parameter and cutpoints that identify boundaries between the ordered outcomes. The probability of observing outcome $k$ or higher for item $i$ and person $j$ is given by Eq. 1 .

$\operatorname{Pr}\left(Y_{i j} \geq k \mid \theta_{j}\right)=\frac{\exp \left\{a_{i}\left(\theta_{\mathrm{j}}-\mathrm{b}_{\mathrm{ik}}\right)\right\}}{1+\exp \left\{a_{i}\left(\theta_{\mathrm{j}}-\mathrm{b}_{\mathrm{ij}}\right)\right\}} \theta_{\mathrm{j}} \sim N(0,1)$

Where $a_{i}$ represents the discrimination of item $i, b_{i k}$ is the kth cut-point for item $i$, and $\theta_{\mathrm{j}}$ which takes a value of any real number is the latent trait of person $j$. The cut-point $b_{i k}$ can be considered as the difficulty of responding with category $\mathrm{k}$ or higher for item $i$.

Measure of reliability of the use of the instrument is done based on assessment of internal consistency which investigates the proportion of variance accounted for by the estimator of a respondent's trait level. A direct index of reliability for Bayesian scores for the sample data can be calculated as Eq. 2 .

Reliability $=\left(\frac{s_{\overparen{\theta}}^{2}}{s_{\overparen{\theta}}^{2}+\bar{s}_{e}^{2}}\right)$

Where $s_{\overparen{\theta}}^{2}$ is the variance of the score estimates (in other words, the observed score variance) and $\bar{s}_{e}^{2}$ is the average squared standard error, calculated as the mean of the squared standard errors for the examinees in the sample.

However, as the metric is scaled such that the direct estimate of the variance of $\theta$ is equal to 1 , then the variance of the Bayesian score estimates is an estimate of the reliability (DeMars, 2010) which, in this case, is the square of the standard deviation of the estimated scores. Validity of the instrument's usage was verified through examination of the correlation between the constructs and other variables which the construct should predict.

Once demonstrated innovativeness for each sample household heads had been estimated, the results obtained were used for further analysis of factors affecting innovativeness using multiple linear regression. The multiple regression model employed was specified as Eq.3.

$y=\beta_{0}+\beta_{1} X_{1}+\beta_{2} X_{2}+\beta_{3} X_{3}+\ldots \beta_{k} X_{k}+u$

Where $\beta_{0}$, is the intercept, $\beta_{1}$ is the parameter associated with explanatory variable $X_{1}, \beta_{2}$ is the parameter associated with explanatory variable $X_{2}$ and so on. The variable $u$ is the error or disturbance term. It contains factors other than $X_{1}, X_{1}, \ldots, X_{k}$ that affect $y$. In equation 3 $y$ represents innovativeness score. Explanatory variables used in the regression model are described in Table 1.

\section{RESULTS AND DISCUSSION}

\section{Prevalence of Innovativeness among Smallholder Farmers}

Demonstrated innovativeness among smallholder was assessed through 8-item Likert scale instrument followed by 5 -point responses $($ Never $=1$, rarely $=2$, sometimes $=$ 3 , often $=4$, always $=5$ ) that is adapted from Janssen, (2000) scale for assessment of individual innovative behaviour in the workplace. A Mokken procedure conducted for ensuring unidimensionality and local independence assumption with the help of msp module in STATA 14 proved that the scale qualified Mokken scale with all items. Smallholders' level of demonstrated innovativeness has been estimated through graded response model. The score distribution was estimated along with the item parameters, on the same metric as the item parameters. The metric was set such that the mean perception level was 0 with a standard deviation of 1 which is one of the standard ways of employing the model (Embretson and Reise, 2000). The graded response model output for innovativeness is shown in Table 2.

The approximate overall goodness of fit of the fitted model has been assessed using limited-information fit statistics as suggested by Maydeu-Olivares and Joe (2014) using flexMIRT software program. The estimated sample bivariate root mean square error of approximation was found to be 0.06 which is better than the recommended adequate fit cutoff value $\leq 0.089$. A direct index of reliability for Bayesian scores for the sample data is calculated to be 0.88 whereas the Cronbach's alpha measure of reliability is 0.91 based on total number score. It was also attempted to assess the validity of the innovativeness measurement scale by empirically evaluating the correlation between it and dependency syndrome, TLU and farm tool possession. The assumption was that innovative people will not be characterized by dependency syndrome and will possess more productive asset such as TLU and farm tools. On these bases innovativeness was expected to be negatively correlated with dependency syndrome and positively with TLU and farm tool possession. Though weak, the correlation results obtained confirmed the presumed directions giving positive evidence on the validity of the instrument used for measuring innovativeness. 
Table 1 Description of the variables hypothesized to influence smallholders' innovativeness

\begin{tabular}{|c|c|c|c|}
\hline Variables & Variable description & Measurement & sign \\
\hline perception & measure of perception about PSNP & scale & + \\
\hline dependsynd & measure of effort exerted on own farm job & scale & - \\
\hline psnpmem & participation in PSNP & Nominal (yes $=1$ ) & + \\
\hline agroecol & agro-ecological zone in which the household lives and operates & Nominal (lowland $=1$ ) & + \\
\hline $\operatorname{Sex}(\operatorname{sex})$ & sex of the household head & Nominal $($ male $=1)$ & + \\
\hline age65 & state of being under the age of 65 & Nominal (below $65=1$ ) & + \\
\hline marital & marital status of the household head & Nominal (maried $=1$ ) & + \\
\hline hhheduc & education level of the household head & Scale & + \\
\hline hmaxed & $\begin{array}{l}\text { maximum level of education attained by member of the household } \\
\text { other than the head }\end{array}$ & Scale & + \\
\hline hhsize & number of member of the household & scale & + \\
\hline credit & amount of credit taken by the household since 2015 & scale & + \\
\hline training & frequency of participation in extension trainings or field day visits & scale & + \\
\hline irrgacce & household's access to irrigation & Nominal (yes $=1$ ) & - \\
\hline farmfert & satisfaction on perceived fertility of farm plots & Nominal (satisfied $=1$ ) & - \\
\hline lnfarmtool & possession of farm tools in monetary value & scale & + \\
\hline lntlu & possession of livestock in tropical livestock units (TLU) & scale & + \\
\hline massmedi & use of mass media & Nominal (yes $=1$ ) & + \\
\hline lnfarmdist & $\begin{array}{l}\text { measure of average distance from homestead to farm plots in travel } \\
\text { time units (minutes) }\end{array}$ & scale & + \\
\hline lndistmrkt & $\begin{array}{l}\text { measure of average distance from homestead to nearest market in } \\
\text { travel time units (minutes) }\end{array}$ & Scale & + \\
\hline lndistroad & $\begin{array}{l}\text { measure of average distance from homestead to all-weather road in } \\
\text { travel time units (minutes) }\end{array}$ & Scale & + \\
\hline extworcon & measure of external work contact (De Jong and Den Hartog, 2008) & scale & + \\
\hline fatalism & measure of fatalistic outlook (Esparza, Wiebe, and Quiñones, 2015) & scale & - \\
\hline selfeffic & measure of perceived self-efficacy (Schwarzer, 1992) & scale & + \\
\hline jobcontrol & measure of perceived job control Janssen (2000) & scale & + \\
\hline jobdemand & measure of household head's perceived job demand (Janssen, 2000) & scale & + \\
\hline persenvtfit & $\begin{array}{l}\text { measure of perceived person-environment fit (Cable and Derue, } \\
\text { 2002) }\end{array}$ & scale & + \\
\hline intrinsic & measure of intrinsic motivation towards farming job (Ryan, 1982) & scale & + \\
\hline
\end{tabular}

Table 2 shows the estimated item parameters. The thresholds, each, indicate the point at which $50 \%$ of the smallholders with the same demonstrated innovativeness level with the thresholds would choose the designated option or higher. Everyone has a $100 \%$ chance of choosing "Never" or higher, so there is no threshold for that option. For item In1, the probability of choosing "Rarely" is 0.5 for a subject with innovativeness equal to 0.2122 ; the probability of choosing "Sometimes" is 0.5 for a subject with innovativeness equal to 0.6275 ; the probability of choosing "Often" is 0.5 for a subject with innovativeness equal to 1.1076 and the probability of choosing "Always" is 0.5 for a subject with innovativeness equal to 1.7221 . The metric of these values is set by the innovativeness distribution. The mean innovativeness was set to 0 , with a standard deviation of 1 . The thresholds are to be interpreted relative to this distribution. The slope is an index of how rapidly the response probability changes as innovativeness increases.

As can be noticed from the pictorial representation of the order of the mean of estimated difficulty levels of the items, in Figure 1 above, it can be said that more than $50 \%$ percent of the smallholders in the study area have less than $50 \%$ chance of responding positively to all items in the scale for measuring innovativeness. This implies that the majority of the study population has demonstrated innovativeness level below all items in the scale used for measuring innovativeness. Or, $87.5 \%$ of the thresholds in the scale are above the midpoint of the distribution (which is 0 mean) of innovativeness in the corresponding population. The same implication could be extracted from the test characteristic curve depicted in Figure 2.

If the study population is arbitrarily categorized based on the expected scores as "less innovative" [8 -18.67] "medium innovative" (18.67-29.34] and "highly innovative" (29.34 - 40], the percentage of respondents who fall in the first class amounts to $69.5 \%$ while those who fall in the second and third classes cover $23.42 \%$ and $7.08 \%$ respectively. All in all, the majority $(69.5 \%)$ of the study population falls in the "less innovative" class; the proportion that the other two classes cover is only $30.5 \%$.

\section{Determinants of smallholders' innovativeness}

In identifying determinants of smallholders' innovativeness, the innovativeness score predicted by the graded response model was used as dependent variable in this analysis. In the independent variables set, factors related with demography, socio-economy, geospatial and access to infrastructural facilities, psycho-behavioural characteristics and other contextual settings have been included. The multiple linear regression (ordinary least square) model outputs are depicted in the Table 3. 
Table 2 Graded response model results for estimated parameter of items in the innovativeness scale

\begin{tabular}{|c|c|c|c|c|c|c|c|c|c|c|c|}
\hline \multirow[b]{3}{*}{ Item } & & & \multicolumn{8}{|c|}{ Response categories } & \multirow[b]{3}{*}{ MID } \\
\hline & \multicolumn{2}{|l|}{ Slope } & \multicolumn{2}{|l|}{ Rarely } & \multicolumn{2}{|l|}{ Sometimes } & \multicolumn{2}{|l|}{ Often } & \multicolumn{2}{|l|}{ Always } & \\
\hline & Coef. & SE & Threshold & SE & Threshold & SE & Threshold & SE & Threshold & SE & \\
\hline In1 & 2.9472 & 0.2665 & 0.2122 & 0.0643 & 0.6275 & 0.0681 & 1.1076 & 0.0827 & 1.7221 & 0.1214 & 0.9174 \\
\hline In 2 & 1.6293 & 0.1433 & -0.6901 & 0.0974 & 0.4060 & 0.0829 & 1.6919 & 0.1457 & 2.8787 & 0.2755 & 1.0716 \\
\hline In 3 & 1.5398 & 0.1840 & 0.8388 & 0.1023 & 1.4880 & 0.1541 & 2.2167 & 0.2304 & 3.1268 & 0.3602 & 1.9176 \\
\hline In 4 & 2.9381 & 0.2351 & -0.5295 & 0.0733 & 0.4242 & 0.0650 & 1.1039 & 0.0811 & 1.8832 & 0.1322 & 0.7204 \\
\hline In5 & 4.1638 & 0.3863 & -0.0275 & 0.0603 & 0.6665 & 0.0634 & 1.2571 & 0.0812 & 1.7727 & 0.1165 & 0.9172 \\
\hline In6 & 4.9134 & 0.5135 & 0.1669 & 0.0578 & 0.7308 & 0.0628 & 1.2820 & 0.0796 & 1.8594 & 0.1251 & 1.0098 \\
\hline In 7 & 3.1006 & 0.2601 & -0.4036 & 0.0692 & 0.5738 & 0.0667 & 1.1130 & 0.0805 & 1.8855 & 0.1324 & 0.7922 \\
\hline In 8 & 3.5000 & 0.3155 & 0.0980 & 0.0621 & 0.5374 & 0.0637 & 0.9525 & 0.0721 & 1.3726 & 0.0925 & 0.7401 \\
\hline
\end{tabular}

Source: Survey data, 2018.

Note: $\mathrm{SE}=$ Standard error MID = Mean item difficulty

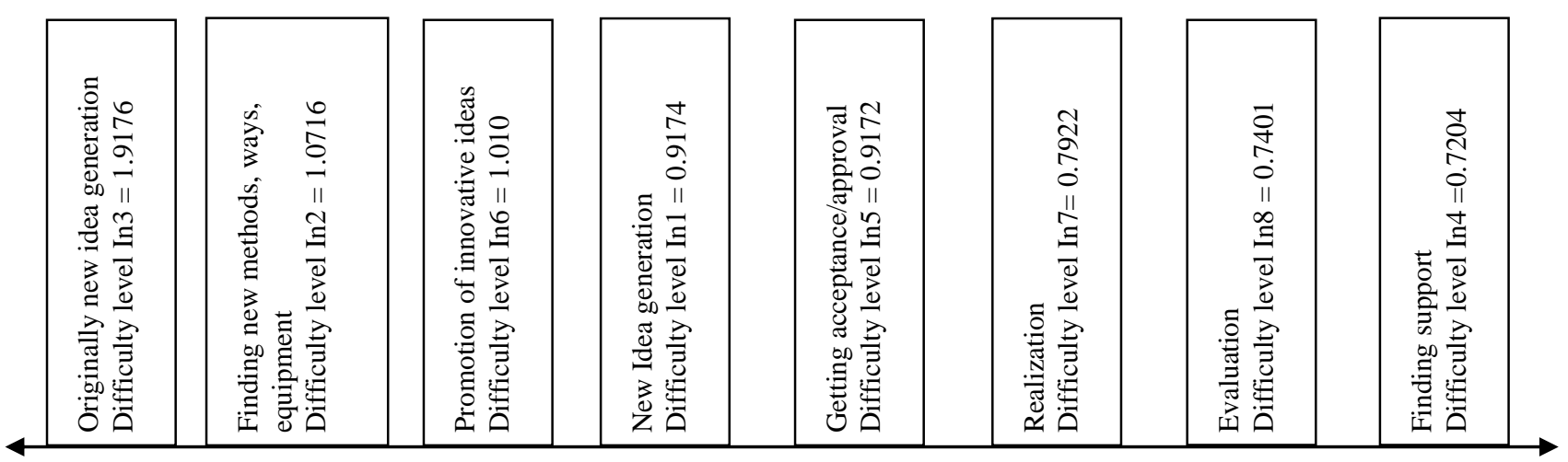

Figure 1 Order of items in the innovation measurement scale based on difficulty level

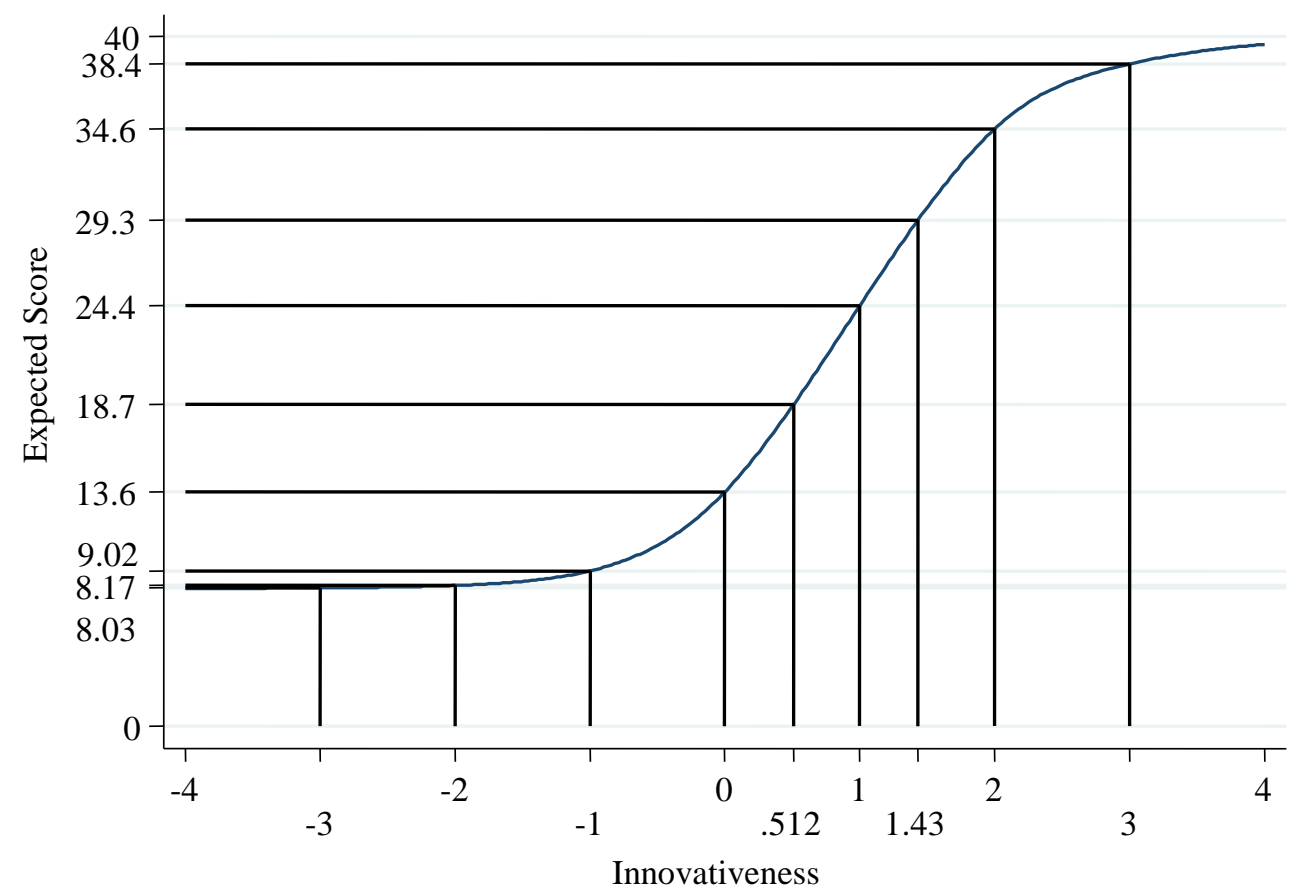

Figure 2 Test characteristic curve of the scale for measuring innovativeness

Among the independent variables included in the model which turned out to be statistically significant at different significance levels, mass media exposure (massmedi), external work contact (extworcon), job- demand (jobdemand), person-environment-fit (persenvtfit), smallholders' perception about PSNP (perception), farm tool possession (lnfarmtool), TLU (lntlu) and distance to all-weather road (Indistroad) are 
found to be positive predictors of innovativeness while agro-ecology (agroecol), access to irrigation (irrgacce), perceived farm plot fertility (farmfert), fatalism (fatalism) and dependency syndrome (dependsynd) are identified as negative predictors.

The positive effect of job demand (jobdemand) and person-environment fit (persenvtfit) on demonstrated innovativeness go in line with the finding of Janssen (2000). Literature on the effect of job-demand as a psychological stressor says that workers who are engaged in a stressful work environment tend to look for innovative way outs in dealing with the situation (Bunce and West 1994; Janssen, 2000; Martín et al., 2007). The finding here, in this regard, agrees with the literature in that a farming situation with relatively higher job-demand and farther from all-weather road are associated with higher level of demonstrated innovativeness. On the other hand, the finding on the effect of person-environment-fit on innovativeness agrees with empirical findings of previous studies of Pee (2012), Sharifirad (2013), and Afsar and Rehman (2015).

The positive association between innovativeness and external work contact is also in accord with the empirical finding of De Jong and Den Hartog (2008), Ndunda and Mungatana (2013) and Chindime et al. (2017). The pieces of informative experience and perspective people may get in their contact with diversified external agents may hint on innovative option (Hermans et al., 2015). Similarly, mass media exposure could play the same role and affect innovativeness positively.

Better possession of farm tools and livestock holding (TLU) and perceiving PSNP as accurately as possible in relation to its intents predicted innovativeness positively. Better possession of farm tools and TLU may imply better flexibility and provision of inputs which might be conducive to innovativeness, a result similar with the findings of Hermans et al. (2015), Lowitt et al. (2015) and Ndunda and Mungatana (2013). On the other hand, the degree to which the introduction of PSNP may affect the economic and other behaviours of smallholders may depend on the extent to which the program is perceived correctly by the community. If it is perceived as a temporary help (i.e. to be discontinued after 5 years once a beneficiary qualify for graduation) to the poor of the poorest that intended to contribute in the prevention of household asset depletion, then given these assumptions beneficiaries of PSNP who perceived the program better may attempt to make use of the help provided to them from PSNP either in kind or cash as a shield for the possible risks associated with innovative engagements. Similarly, non-beneficiaries who better perceive the purpose of the program may stick to their own innovative efforts.

Table 3 Regression model result for estimating factors affecting innovativeness

\begin{tabular}{lrrrr}
\hline Regressors & Coef. & Std. Err. & \multicolumn{1}{c}{$\mathrm{t}$} & \multicolumn{1}{c}{$\mathrm{P}>\mathrm{t}$} \\
\hline perception & 0.0701 & 0.0417 & 1.68 & $0.093^{*}$ \\
dependsynd & -0.1702 & 0.0453 & -3.76 & $0.000^{* * *}$ \\
psnpmem & 0.0299 & 0.0715 & 0.42 & 0.676 \\
agroecol & -0.2753 & 0.1233 & -2.23 & $0.026^{* * *}$ \\
sex & 0.0902 & 0.1549 & 0.58 & 0.560 \\
age65 & -0.0402 & 0.1595 & -0.25 & 0.801 \\
marital & 0.1201 & 0.1622 & 0.74 & 0.460 \\
hhheduc & 0.0132 & 0.0132 & 1.00 & 0.317 \\
hmaxed & 0.0146 & 0.0120 & 1.22 & 0.223 \\
hhsize & -0.0221 & 0.0183 & -1.20 & 0.229 \\
lncredit & -0.0086 & 0.0136 & -0.63 & 0.531 \\
training & -0.0049 & 0.0104 & -0.47 & 0.637 \\
irrgacce & -0.2357 & 0.1295 & -1.82 & $0.069^{*}$ \\
farmfert & -0.2230 & 0.0706 & -3.16 & $0.002^{* * *}$ \\
lnfarmtool & 0.0404 & 0.0171 & 2.37 & $0.018^{* * *}$ \\
lntlu & 0.1897 & 0.0711 & 2.67 & $0.008^{* * *}$ \\
massmedi & 0.2084 & 0.0984 & 2.12 & $0.035^{* *}$ \\
lnfarmdist & -0.0453 & 0.0335 & -1.35 & 0.177 \\
lndistmrkt & -0.0770 & 0.0499 & -1.54 & 0.123 \\
lndistroad & 0.0512 & 0.0296 & 1.73 & $0.085^{*}$ \\
extworcon & 0.3484 & 0.0530 & 6.57 & $0.000^{* * *}$ \\
fatalism & -0.0927 & 0.0434 & -2.14 & $0.033^{* *}$ \\
selfeffic & -0.0462 & 0.0451 & -1.02 & 0.306 \\
jobcontrol & -0.0374 & 0.0397 & -0.94 & 0.347 \\
jobdemand & 0.2122 & 0.0454 & 4.67 & $0.000^{* * *}$ \\
persenvtfit & 0.1297 & 0.0446 & 2.91 & $0.004^{*} * *$ \\
intrinsic & 0.0683 & 0.0460 & 1.49 & 0.138 \\
_Cons & 0.1772 & 0.3476 & 0.51 & 0.610
\end{tabular}

Number of obs $=476, F(27,448)=15.27$, Prob $>F=0.0000$, R-squared $=0.4792$,

Adj R-squared $=0.4478$, Root MSE $=0.6986$

Source: Field survey data, 2018. ;Note: ***Significant at $1 \%$ level; **significant at $5 \%$ level; *significant at $10 \%$ level. 
It was assumed that the relatively harsher physical environment in the lowlands of Fedis district (Magen, 2014; Carmi, 2016) could be a factor that adds to the stressfulness of the farming occupation which precipitates an innovative way out. However, the result found here turn out to be the opposite. One possible reason can be the unsatisfactory response of the production environment that may affect smallholders' perceived effort-reward fairness. If fairness is not felt, that could be bottleneck to innovative engagement. Crudely, in contrast to Haramaya's midland agro-ecology, the undependability of the lowland agro-ecological nature of Fedis district (Belaineh and Drake, 2005) may create the feeling of unrewarding work environment; a sentiment that could possibly discourage innovative engagement.

The fact that fatalism and dependency syndrome affect innovativeness negatively is what is expected. The theory of self-determination emphasizes that internal motivation plays vital role in one's effort to understand his surrounding environment and respond to demanding life situations (Deci and Ryan, 1985). However, one's tendency to believe that people have no control over whatever may happens to them or the expectation that external agents, such as social protection programs, will take care of one's life requirements, may hamper the believer's motivation to innovatively address those demanding situations. What makes it worse is the pervasive tendency of research participants to associate fatalism with religious thoughts.

The other variables that are negatively associated with innovativeness are possession of fertile farmland and access to irrigation. In a work place that is characterized by high job-demand, among the main factors that contribute for employees to approach the stressful work situation innovatively, one is the workers strong desire to relieve themselves from the stress by finding innovative ways of accomplishing their task (Janssen, 2000). With this assumption in mind and keeping other things constant, farmers with possession of fertile farmland and access to irrigation may not opt for thinking out of the box to fulfil their household consumption. Running their business as ordinarily as possible may be enough to satisfy their household needs. The person with possession of fertile farmland and/or access to irrigation, in relative terms, may not be in a pressing situation to find an innovative way out. This means that possession of fertile farmland or having access to irrigation may not encourage innovativeness.

Information from key informants and focus group discussion indicated that it is not customary to observe smallholders carrying out their farming activity differently (innovatively) from the usual traditional way. Additionally, it was said that, generally, let alone supporting innovative engagement, the meagreness of the support provided by PSNP to beneficiaries made it impossible for the vast majority of beneficiaries to escape the problems of food insecurity in a way presumed by the program. Besides, it was indicated that beneficiaries of PSNP are not that much committed to make necessary efforts to utilize the favourable condition created by the program and change their life condition.

\section{CONCLUSION}

In this study, it was intended to assess smallholder farmers' innovativeness and identify its determinants. The results indicated that innovativeness level was found to span, predominantly, the "less innovative" class. The portion that "high innovative" class cover is less than one tenth. Innovativeness is found to be positively predicted by smallholders' perception of PSNP, farm tools possession, livestock holding, external work contact, perceived person-environment fit, job demand and distance to all-weather road, and negatively by agroecology (lowland), access to irrigation, farmland fertility and fatalism. The finding here signal a big threat to the portion of the rural farming community, and the country at large, who might be depending on outdated backward ways of agricultural production techniques. It is mandatory that the farming community looks for new and innovative ways of production to cope up with the dynamics in the economic, social and physical environment or continue facing the extant food insecurity problems. Therefore this is a big assignment to the government. The findings of this research point out the following recommendations.

Program owners of PSNP should work to enhance smallholders' perception about the program, as better perception encouraged them to be better innovative. Motivational extension work to raise the level of trust smallholder should envision regarding the dependability of their farming occupation should be planned and effected as these have influence on their innovative engagement.

It is instrumental to provide smallholders with external exposure and training to improves their skill so as to make them better fit with their farming occupation and motivating them to have confidence on their own ability to tackle life challenges which can help them learn better ways of doing agriculture, avoid dependency syndrome and exploit their innovative potential

It is helpful to expand the level of exposure that smallholders have to mass media programs that initiate and strengthen innovative engagements. Extension service provider should be able to provide smallholders with audio visual documentation of others' successful works.

Strong motivational extension service has to be implemented to aware smallholders to exploit the productive potential they have as it is observed that those with access to irrigation and better farm fertility to be less creative to find better ways of production.

The extension service institution in the study area need to work in collaboration with Muslim religious leaders in the study area since fatalistic outlook was found to impede smallholders from being more innovative and as smallholders associated fatalism with religious thoughts.

\section{Acknowledgements}

The authors are grateful to those who lent their hands in the data collection process and to Haramaya University. 


\section{REFERENCES}

AFSAR, B., \& REHMAN, M. (2015). The relationship between workplace spirituality and innovative work behavior: the mediating role of perceived person organization fit. Journal of Management, Spirituality \& Religion, 12(4), 329-353. DOI: 10.1080/14766086.2015.1060515

AMABILE, T. M. (1997). Motivating creativity in organizations. California Management Review, 40(I), 3959. DOI: $10.2307 / 41165921$

BEDUSCHI, L.C., CONTRERAS, R., \& HOLZ, R. (2017). Innovation for Sustainable Rural Development: Towards a theoretical framework. In FAO / Imanol Camblor, Innovation for Sustainable Rural Development (pp. 1-8). Santiago, Chile: Retrieved from http://www.fao.org/3/a-i7769e.pdf

BELAINEH, L., \& DRAKE, L. (2005). Determinants of smallholder farmers' perceptions of risk in the Eastern Highlands of Ethiopia. Journal of Risk Research, 8(5), 383-416. DOI: $10.1080 / 1366987042000192426$

BUNCE, D., \& WEST, M. (1994). Changing work environments: Innovative coping responses to occupational stress. Work \& Stress, 8(4), 319-331. DOI: https://doi.org/10.1080/02678379408256539

CABLE, D. M., \& DERUE, D. S. (2002). The Convergent and Discriminant Validity of Subjective Fit Perceptions. Journal of Applied Psychology, 87(5), 875-884. DOI: 10.1037//0021-9010.87.5.875

CARMI, D. (2016). The Gender Dimensions of Drought in Fedis Woreda District, Ethiopia (No. 2016-8). Geneva, Switzerland

CHINDIME, S., KIBWIKA, P., \& CHAGUNDA, M. (2017). Determinants of sustainable innovation performance by smallholder dairy farmers in Malawi. Cogent Food \& Agriculture, 3(1), 1-11. DOI: 10.1080/23311932.2017.1379292

CSA (Central Statistical Agency). (2007). The 2007 Population and Housing Census of Ethiopia: Statistical Report for Oromiya Region; Part I: Population Size and Characteristics. Addis Ababa.

CSA (Central Statistical Agency). (2016). Key Findings of the 2015/2016 (2008 E.C) Agricultural Sample Surveys. Addis Ababa.

DE JONG, J., \& DEN HARTOG, D. (2008). Innovative Work Behavior: Measurement and Validation (EIM Research Reports referrence No. H200820). Zoetermeer, The Netherlands.

DECI, E. L., \& RYAN, R. M. (1985). Intrinsic Motivation and Self-Determination in Human Behavior. New York: Springer Science+Business Media.

DEMARS, C. (2010). Item Response Theory: Understanding Statistics Measurement. (N. Beretvas \& P. Leavy, Eds.). New York: Oxford University Press, Inc.

DEVEREUX, S., \& SABATES-WHEELER, R. (2004). Transformative social protection. Institute of Development Studies Working Paper 232. Brighton, England.

EMBRETSON, S. E., \& REISE, S. P. (2000). Item Response Theory for Psychologists. Mahwah, New Jersey: Lawrence Erlbaum Associates, Inc.
EPCC (Ethiopian Panel on Climate Change). (2015). First Assessment Report, Agriculture and Food Security. Addis Ababa: Ethiopian Academy of Science.

ESPARZA, O. A., WIEBE, J. S., \& QUIÑONES, J. (2015). Simultaneous Development of a Multidimensional Fatalism Measure in English and Spanish. Curr Psycho, 34, 597-612. DOI: $10.1007 / \mathrm{s} 12144-014-9272-\mathrm{Z}$

GEBRE, G. G., \& ZEGEYE, D. M. (2014). Challenges of farmers' innovativeness in central zone. International Journal of Agricultural Policy and Research, 2(5), 215223.

HERMANS, F., KLERKX, L., \& ROEP, D. (2015). Structural Conditions for Collaboration and Learning in Innovation Networks: Using an Innovation System Performance Lens to Analyse Agricultural Knowledge Systems. Journal of Agricultural Education and Extension, 21(1), 35-54. 10.1080/1389224X.2014.991113

JANSSEN, O. (2000). Job Demands, Perceptions of Effort-Reward Farness and Innovative Work Behaviour. Journal of Occupational and Organizational Psychology, 73(3), 287-302. DOI: 10.1348/096317900167038

JEMA, H., MENGESHA, Y., TAMIRU, D., \& ALEMU, G. (2010). Aid effectiveness in the WASH sector in Oromia region, Eastern Hararghe zone: The case of Goro-Gutu and Babile wordeas. Addis Ababa.

LOWITT, K., HICKEY, G. M., SAINT VILLE, A., RAEBURN, K., THOMPSON-COLÓN, T., LASZLO, S., $\&$ PHILLIP, L. E. (2015). Factors affecting the innovation potential of smallholder farmers in the Caribbean Community. Regional Environmental Change, 15(7), 1367-1377. DOI:10.1007/s10113-015-0805-2

LUMPKIN, G. T., \& DESS, G. G. (1996). Clarifying the Entrepreneurial Orientation Construct and Linking It to Performance. The Academy of Management Review, 21(1), 135-172. DOI: $\underline{10.2307 / 258632}$

MAGEN, C. (2014). Nutritional Causal Analysis. East Hararghe Zone, Fedis and Kersa Woredas, Ethiopia.

MARTÍN, P., SALANOV, M., \& PEIRÓ, J. M. (2007). Job demands, job resources and individual innovation at work: Going beyond Karasek's model? Psicothema, 19(4), 621-626.

MAYDEU-OLIVARES, A., \& JOE, H. (2014). Assessing Approximate Fit in Categorical Data Analysis. Multivariate Behavioral Research, 49(4), 305-328. DOI: 10.1080/00273171.2014.911075

MOA (Ministry of Agriculture). (2014). Productive Safety Net Programme Programme Implementation Manual Version 1.0. Ministry of Agriculture. Addis Ababa, Ethiopia.

NBE (National Bank of Ethiopia). (2018). 2017/18 Annual Report. National Bank of Ethiopia. Addis Ababa.

NDUNDA, E. N., \& MUNGATANA, E. D. (2013). Determinants of farmers' choice of innovative riskreduction interventions to waste water-irrigated agriculture. African Journal of Agricultural Research, 8(1), 119-128. DOI: 10.5897/AJAR12.1679

OECD (Organisation for Economic Co-operation and Development). (2009a). Growing prosperity: Agriculture, economic renewal and development. DCD/DAC(2009)36. Organisation for Economic Co-operation and Development. Paris, France. 
OECD (Organisation for Economic Co-operation and Development). (2009b). Promoting Pro-Poor Growth: social protection. Organisation for Economic Cooperation and Development. Paris, France.

PEE, L. G. (2012). The Effects of Person-Environment Fit on Employees' knowledge Contribution. In M.-H. Huang, G. Piccoli, \& V. Sambamurthy (Eds.), Knowledge Management and Business Intelligence (pp. 1-19). Orlando. Retrieved from http://aisel.aisnet.org/icis2012/proceedings/KnowledgeM anagement/1 /

RYAN, R. M. (1982). Control and Information in the Intrapersonal Sphere: An Extension of Cognitive Evaluation Theory. Journal of Personality and Social Psychology, 43(3), 450-461. DOI: apa.org/journals/psp/43/3/450.pdf

SCHILLING, M. A. (2017). Strategic Management of Technological Innovation (5th ed.). New York: McGrawHill Education.

SCHWARZER, R. (1992). Self-Efficacy: Thought Control of Action (Hemisphere). Washington DC: Hemisphere.
SHARIFIRAD, M. SADEGH. (2013). Transformational leadership, innovative work behaviour, and employee well-being. Global Business Perspective, 1(3), 198-225. DOI: $10.1007 / \mathrm{s} 40196-013-0019-2$

TIRFE, A. G. (2014). Smallholder farmers' innovation and its determinants the case of Hirity Mekan seed producers' cooperative, Tigray, Ethiopia. Developing Country Studies, 4(21), 104-114.

TOLOSSA, D., \& TAFESSE, T. (2008). Linkages between Water Supply and Sanitation and Food Security: A case study in four villages of East Hararghe zone, Oromia region (No. 6). Research-inspired Policy and Practice Learning in Ethiopia and the Nile region. Addis Ababa.

WORLD BANK. (2012). Agricultural Innovation Systems: An Investment Sourcebook. Washington, DC: The World Bank 